\title{
Emotional regulation of pain: the role of noradrenaline in the amygdala
}

\author{
STROBEL Cornelia ${ }^{1}$, HUNT Sarah $^{1}$, SULLIVAN Robert ${ }^{1}$, SUN JianYuan ${ }^{2} \&$ SAH Pankaj ${ }^{*}$ \\ ${ }^{1}$ Queensland Brain Institute, The University of Queensland, Brisbane, Queensland 4072, Australia; \\ ${ }^{2}$ Institute of Biophysics, Chinese Academy of Sciences, Beijing 100101, China
}

Received January 16, 2014; accepted February 25, 2014; published online March 14, 2014

\begin{abstract}
The perception of pain involves the activation of the spinal pathway as well as the supra-spinal pathway, which targets brain regions involved in affective and cognitive processes. Pain and emotions have the capacity to influence each other reciprocally; negative emotions, such as depression and anxiety, increase the risk for chronic pain, which may lead to anxiety and depression. The amygdala is a key-player in the expression of emotions, receives direct nociceptive information from the parabrachial nucleus, and is densely innervated by noradrenergic brain centers. In recent years, the amygdala has attracted increasing interest for its role in pain perception and modulation. In this review, we will give a short overview of structures involved in the pain pathway, zoom in to afferent and efferent connections to and from the amygdala, with emphasis on the direct parabrachio-amygdaloid pathway and discuss the evidence for amygdala's role in pain processing and modulation. In addition to the involvement of the amygdala in negative emotions during the perception of pain, this brain structure is also a target site for many neuromodulators to regulate the perception of pain. We will end this article with a short review on the effects of noradrenaline and its role in hypoalgesia and analgesia.
\end{abstract}

pain, learning, stress, parabrachial

Citation: Strobel C, Hunt S, Sullivan R, Sun JY, Sah P. Emotional regulation of pain: the role of noradrenaline in the amygdala. Sci China Life Sci, 2014, 57: 384-390, doi: 10.1007/s11427-014-4638-x

Pain is a conscious and subjective experience that is evoked in response to a stimulus that causes, or has the potential to cause harm. Different aspects constitute the overall experience of pain; this includes the sensory aspect and the emotional response. Emotions have been proposed to involve two motivational systems: the appetitive system evoked by pleasant stimuli, such as feeding and sex, and the aversive system activated by unpleasant stimuli leading to anxiety and withdrawal or aggression and defensive behavior [1,2].

Pain and negative emotions seem to be able to influence each other reciprocally [2]. Thus, for instance, it has been found that the risk of developing chronic musculoskeletal pain was two-fold in people suffering from depression

*Corresponding author (email: pankaj.sah@uq.edu.au) compared to healthy controls [3] and the severity of depressive symptoms in patients indicated the likelihood to develop neck and back pain [2,4]. In contrast, individuals suffering from chronic pain, such as musculoskeletal pain and daily headaches often suffer from depression and show attention deficits [5]. As an underlying mechanism, it has been suggested that evoking the aversive system by inducing negative emotions (e.g., with aversive pictures), primes this pathway and increases the response of defensive reflexes and the perception of pain. Even though data suggests that pain is enhanced in combination with the activation of aversive feelings, this seems especially to be the case for low threshold, anxiety-inducing aversive stimuli [2,6]. In contrast, stress-induced analgesia is a phenomenon in which fearful and often life-threatening situations (e.g., visual 
re-exposure of war veterans with posttraumatic stress disorder to war, exposure of mice to natural predators) suppresses the perception of pain, which may serve the purpose of fast defensive action, attention and/or flight from the dangerous situation [7-9]. Stressful situations increase the level of noradrenaline in the body $[10,11]$, which acts besides many other neuromodulators, as an important modulator in the perception of pain at the spinal $[12,13]$ and supra-spinal level $[14,15]$.

Chronic pain is still difficult to treat, and is the cause of suffering for many people. Even though the currently available research gives us insight in the processing and modulation of pain, much work still remains to be done to complete the picture of this process. The amygdala is involved in the assessment of emotional aspects and the modulation of autonomic responses (shallow breathing, sweating, increases in blood pressure and heart rate) in relation to pain. In fearful situations, the amygdala seems to be involved in stress-induced analgesia, which is in part modulated by noradrenaline. Modulation of these negative emotions is one component of therapy for pain. Importantly the amygdala, is also involved in assessment of positive emotions, and activation of the appetitive system, that are associated with positive emotions, reduces defensive reflexes $[1,2]$, and more recent approaches in the treatment of pain include cognitive behavioural therapy and relaxation with meditation or music to reduce pain [16-18]. In summary, pain is a multifaceted experience that has an impact on many aspects of emotional life. As the amygdala is a central component in the neural circuitry that processes emotion, understanding the role of the amygdala in anti-nociception will have a clear impact on the development of procedures to improve treatment options in chronic pain. In this paper, we summarize the current state of knowledge about nociception and the amygdala.

\section{Structures involved in the pain pathway}

The detection of mechanical, chemical and thermal noxious stimuli occurs through the stimulation of pain receptors (nociceptors), located at the terminals of $\mathrm{A} \delta$ and $\mathrm{C}$ fibers. These primary afferent fibers carry nociceptive information from the periphery to the dorsal horn of the spinal cord, which in turn projects to a wide range of supraspinal structures, accounting for the multiple dimensions of the pain experience [19].

First, projection neurons from the dorsal horn target a number of regions that are involved in the autonomic response to pain [20-22], such as the periaqueductal grey (PAG), dorsal and ventral medulla, hypothalamus [23] and nucleus of the solitary tract (NTS) [24]. Most of the structures targeted by the dorsal horn are also involved in the modulation of pain, either through direct or indirect projections back to the dorsal horn [20].
The dorsal horn also sends strong projections to the thalamus, which may relay nociceptive information to the cortex responsible for sensory discrimination and motivational responses $[19,25,26]$ and the amygdala, which is involved in the expression of emotions [27,28].

Finally, the parabrachial nucleus in particular receives some of the largest projections from the dorsal horn and in turn projects to PAG, hypothalamus, amygdala as well as back to the dorsal horn, thus potentially playing an important role in both the autonomic and emotional responses to pain [21] and have been found to be involved in the descending inhibition of nociception via the reciprocal connections to the dorsal horn $[8,29]$. These nociceptive inputs are summarized in Figure 1.

\section{Amygdala's connections with other brain areas involved in pain processing}

The amygdala is located in the mid temporal lobe and is comprised of a number of interconnected nuclei. Of these, the basolateral amygdala (BLA), which in simplified models is often described as the input station, receives inputs from all sensory systems [30,31] and the thalamus [32,33]. In contrast, the central amygdala (CeA) is considered to be the major output station, projecting to the hypothalamus, bed nucleus of the stria terminalis and the brainstem [34,35]. These downstream connections of the CeA are involved in eliciting autonomic and endocrine responses to affective stimuli $[35,36]$.

\subsection{Afferents involved in the pain pathway}

Two distinct pathways are involved in communicating nociceptive information to the amygdala. First, the spinothalamic tract sends nociceptive information from the spinal cord to thalamus and hypothalamus. This processed, polymodal information then reaches the lateral amygdala, either directly or indirectly via the granular and dysgranular insular cortex, or the anterior cingulate cortex [37,38]. In addition to this, nociceptive information arrives at the amygdala via the spinopontoamygdaloid tract. This pathway sends purely nociceptive information from the spinal cord to the pontine parabrachial nucleus (pPB), and from there, directly to the $\mathrm{CeA}$, which has been defined as the nociceptive amygdala. Notably, this pathway is bypassing thalamus and lateral amygdala [21,39].

\subsection{Spinopontoamygdaloid pathway}

The lateral part of the pPB receives nociceptive information from where it is conveyed to other brain areas including the extended amygdala [40,41]. The pPB is divided into a number of subregions that project to different parts of the amygdala. Thus, anterograde tracer injections show axon 


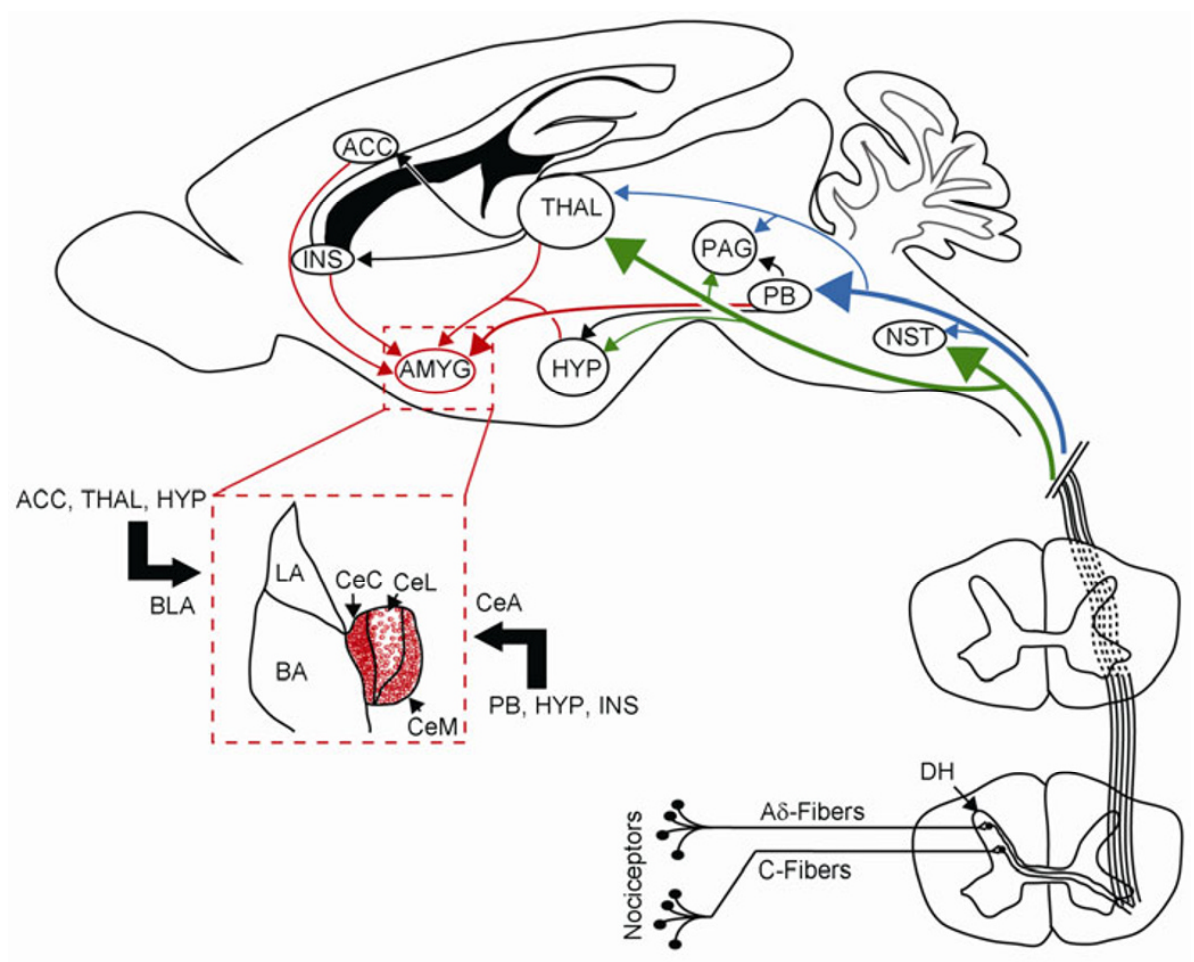

Figure 1 From nociception to emotion: pain circuits involved in direct or indirect projections to the amygdala. Nociceptors are activated by noxious stimuli. The signal is carried along $\mathrm{A} \delta$ - and C-Fibers, which are relayed in the dorsal horn (DH). This nociceptive information reaches the amygdala via the spino-thalamic tract (green) or spinopontoamygdaloid tract (blue). The spino-thalamic tract activates the nucleus of the solitary tract (NST), periacqueductal gray (PAG), hypothalamus (HYP) and thalamus (THAL). The hypothalamus and thalamus will then convey processed nociceptive information directly (red) or indirectly (black) via the activation of the anterior cingulate cortex (ACC) or insular cortex (INS) to the amygdala (AMYG). The spinopontoamygdaloid tract innervates the parabrachial nucleus (PB), which in turn projects to the amygdala. The red dashed boxes show the location of the amygdala in the brain (top) and the amygdala magnified (bottom) with the major nuclei basolateral amygdala (BLA) (lateral amygdala (LA), basal amygdala (BA)) and central amygdala (CeA) (central capsular amygdala $(\mathrm{CeC})$, central lateral amygdala (CeL), central medial amygdala (CeM)). Nociceptive information from the ACC, THAL and HYP reaches the amygdala via the BLA, whereas nociceptive inputs from the PB, HYP and INS target the CeA.

terminals in the central capsular amygdala $(\mathrm{CeC})$ and central medial amygdala (CeM), whereas only moderate innervation is seen in the basolateral amygdala $[42,43]$. In contrast, tracer injections in the lateral region of the $\mathrm{pPB}$ result in terminal labeling not only in the $\mathrm{CeC}$, but also in the central lateral amygdala $(\mathrm{CeL})[40,43,44]$. Inputs from the pPB to the CeA form two distinct types of terminals that have been described as bushy or perisomatic. The bushy type has highly branched terminals with many boutons, can be found throughout all subnuclei of the $\mathrm{CeA}$, and appear to be typical asymmetric glutamatergic synaptic terminals. In contrast, the perisomatic type forms basket-like terminals around somata of neurons, particularly in the CeL part and occasionally in the $\mathrm{CeC}$ [43]. The terminals of this large projection from the parabrachial to the central amygdala are shown in Figure 2.

The functional role of lateral pPB to CeA connections, and their involvement in processing pain has been investigated using electrophysiological recordings in vitro and in vivo as well as fMRI imaging. Initially, electrophysiological recordings in vivo found that the majority $(70 \%)$ of $\mathrm{pPB}$ neurons projecting to the $\mathrm{CeA}$, identified by antidromic stimulation, responded to either noxious mechanical and/or thermal stimulation [39] as well as to noxious visceral stimuli [45]. Most neurons had large receptive fields and were able to respond to stimulation of several parts of the body [39]. Moreover, in vivo single-unit recordings showed that the majority of CeA neurons also responded to noxious superficial (skin) and deep body (joint) mechanical and/or thermal stimuli $[46,47]$ of a wide range of body parts. Most of these nociceptive neurons could be divided into two distinct populations: one group was excited (46\%) and preferentially located in the $\mathrm{CeC}$, whereas the other group was inhibited $(34 \%)$ by noxious stimulation and mainly located in the center of the CeL [45]. In confirmation of these results, fMRI studies in humans have shown besides other brain areas, the activation of the amygdala in response to noxious stimulation [48].

\subsection{Efferents involved in the pain pathway}

Direct projections from the nociceptive amygdala, labeled by using targeted $\mathrm{CeC}$ and $\mathrm{CeL}$ anterograde tracer injections, have been found to the cholinergic basal nuclei, such as the substantia innominata, the hypothalamus which controls autonomic functions such as heart rate and blood pressure, 


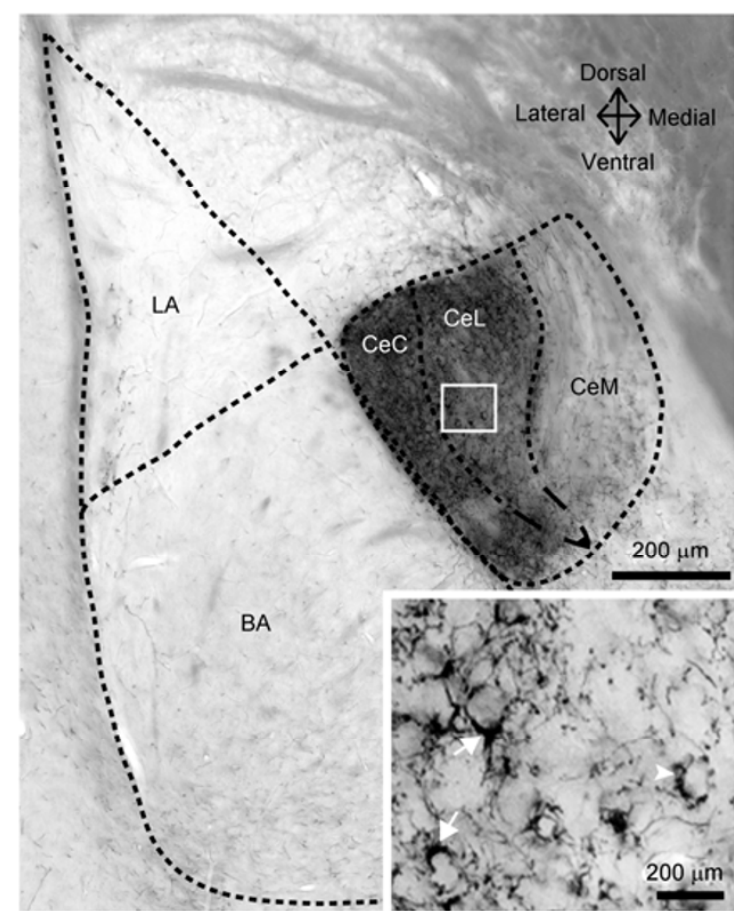

Figure 2 Labeled parabrachial nucleus projections in the central amygdala from a coronal section of mouse brain. Basal amygdala (BA), lateral amygdala (LA), capsular (CeC) and lateral (CeL ) and medial (CeM) divisions of the central amygdala nuclei are outlined in black dashed lines and medial, lateral, dorsal and ventral have been indicated for orientation. The white-boxed region in the CeL corresponds to the higher magnification inset image. Labeled putative synapses surrounding the cell bodies of neurons in the central amygdala exhibited either a bushy type morphology which are highly branched with multiple buttons (arrowhead) or larger perisomatic type (arrows), which were only identified in the $\mathrm{CeC}$ and $\mathrm{CeL}$ divisions. Adult C57BL6 $(n=6,<\mathrm{P} 35)$ were deeply anaesthetized with an intra-peritoneal injection of ketamine $(10 \%)$ and xylazine $(5 \%)$ in saline at $100 \mu \mathrm{L}$ per $10 \mathrm{~g}$. Animals were placed into a stereotactic apparatus and heads secured with ear bars and a mouthpiece. Body temperature was maintained using a heating pad set at $35^{\circ} \mathrm{C}$. The skull was exposed using a scalpel blade and Bregma determined. Holes were drilled through the skull at the coordinates (Bregma -0.52 , medial/lateral $+/-0.15$ and dorsal/ ventral -0.26) established from the mouse brain atlas. Glass electrodes with a long tapered shaft and a 30-50 $\mu \mathrm{m}$ diameter hole were filled with $0.25 \mu \mathrm{L}$ of the biotinylated dextrans tracer $(5 \%$ BDA, $10000 \mathrm{MW}$, molecular probes) and stereotatically injected bilaterally into the parabrachial nucleus. Animals were then removed from the stereotactic stage and the ski over the incision site sealed using Vetbond. Animals were injected subcutaneously with enrofloxacin $(1 \mu \mathrm{L}$ per $10 \mathrm{~g})$, a fluoroquinolone antibiotic, and torbugesic $(2.5 \mu \mathrm{L}$ per $10 \mathrm{~g})$, a centrally acting analgesic, both made up to $0.5 \mathrm{~mL}$ in saline. Animals were allowed to recover for $7 \mathrm{~d}$. Animals were anaesthetized with an over dose of sodium pentobarbital (Lethabarb, $100 \mathrm{mg} \mathrm{kg}^{-1}$ intraperitoneal) and perfusion fixed transcardially with saline $(0.9 \% \mathrm{NaCl})$ followed by $4 \%$ paraformaldehyde, $0.5 \%$ glutaraldehyde in $0.1 \mathrm{~mol} \mathrm{~L}^{-1}$ phosphate buffer. Brains were removed and immersion fixed in the same fixative for $3 \mathrm{~h}$ and then washed in phosphate buffered saline $(0.1$ mol L ${ }^{-1}$ PBS). $50 \mu \mathrm{m}$ thick sections were cut using a vibratome (Lecia 1000s) and labeled with streptavidin horseradish peroxidase for $16 \mathrm{~h}$ at room temperature. Labeling was revealed using 3,3'-Diaminobenzidine (DAB) as a chromagen. Sections were mounted onto glass slides, visualized and imaged using Axio Imager Z1 microscope with a Zeiss AxioCam HRc digital camera. This work was approved by the University of Queensland Animal Ethics Committee and experiments were carried out in accordance with National Health and Medical Research Council of Australia guidelines. Adequate measures were taken to minimize pain or discomfort to animals. and the bed nucleus of the stria terminalis, which can influence the autonomic system [49,50]. However, most tracer studies did not distinguish between subnuclei in the CeA, and include the CeM. Projections from the CeA have also been found in the PAG, the parabrachial nucleus and the nucleus of the solitary tract, all of which are involved in descending control of nociception [51-54]. Finally, the CeA also influences the forebrain via indirect projections with projections to cortical areas (orbital and medial prefrontal cortices, agranular insular cortex) involved in cognitive processes such as attention, consciousness, discrimination of pain signals and decision making, and the dorsal thalamus, which processes information from sensory systems [55].

\section{The amygdala and the modulation of per- ceived pain}

It has long been appreciated that persistent pain can be modified by emotional and psychosocial factors. The amygdala is ideally situated to play a key role in the emotional modulation of pain due to its afferent and efferent projections to and from brain areas involved in nociception and autonomic responses, important for the expression of emotions such as fear. Indeed, the amygdala appears to be involved in the enhancement (hyperalgesia), as well as in the reduction or inhibition (hypoalgesia/analgesia) of pain signals.

Evidence for a role of the amygdala in the enhancement or reduction of nociception comes from behavioural experiments. Hyperalgesia to previous electrical tail shocks in rats was measured as a reduction in the vocalization threshold. In CeA lesions this effect was abolished, suggesting a role in sensitization [56]. In addition, bilateral lesions of the amygdala lead to an increase in the pain threshold in rats measured as the time of vocalization in response to increasing electrical tail stimulation [57], suggesting a role in the expression of pain. In contrast, a role of the amygdala in hypoalgesia is suggested by unilateral stimulation of the amygdala, which led to a reduction in pain behavior during tail flick experiments [58]. In addition, central amygdala lesions attenuated stress-induced analgesia to different stressors, such as the exposure to predators, electrical footshock and re-exposure to environments associated with footshock $[8,59]$.

\subsection{Analgesic and hypoalgesic neuromodulation by noradrenaline}

The number of neuromodulators and the diversity of their effects on the perception of pain in structures involved in nociception is immense and would exceed the scope of this review. Here we will concentrate on the hypoalgesic and analgesic effects promoted by noradrenaline with the focus 
of its action in the amygdala. Earlier studies suggested that the analgesic effect of noradrenaline occurs at the level of the spinal cord. However, since then there has been cumulative evidence for noradrenergic modulation at supra-spinal levels, which involves several brain areas (for review see [20]). Noradrenergic receptors can be found in all supraspinal structures that are involved in pain processing, even though the exact mechanism of action is still not understood [15].

Several findings support the amygdala as a target site for noradrenaline involved in pain modulation during heightened emotional states. The central amygdala is densely innervated by the noradrenergic system, and receives its main adrenergic fibers from the locus coeruleus and a smaller noradrenergic input from the ventrolateral medulla [60,61]. Noradrenaline levels in the amygdala are increased in response to stressful situations as revealed by microdialysis $[62,63]$. In addition, almost all types of adrenergic receptors are present in the central amygdala. Evidence for $\alpha_{1}$-receptor activation was revealed in the central amygdala in animal pain model with injection of formalin in the mouse hindpaw [64]. Immunolabelling has shown $\alpha_{1 b}$-adrenoceptors in the basolateral and CeA [65], $\alpha_{2 \mathrm{a}^{-}}$[66] and $\alpha_{2 \mathrm{c}}$ [67] in various nuclei including $\mathrm{CeL}$ and $\mathrm{CeC}$, whereas $\alpha_{2 b}$-noradrenergic receptors do not appear to be present [68]. Weak labeling in the amygdala has also been seen for beta-adrenergic receptors $[69,70]$. As described above, the parabrachial input, carrying nociceptive information, forms single-fiber perisomatic basket terminals in the CeL that has multiple release sites. These glutamatergic synapses have all-or-nothing responses with fixed amplitudes, independent of stimulation strength, and release of noradrenaline depresses these synapses [71]. Thus, release of noradrenaline effectively reduces nociceptive sensory input into the CeA. Interestingly, behavioral experiments have shown that intrathecal injection of $\alpha_{2}$ adrenergic receptor agonists has analgesic functions [72]. More specifically, microinjection of the $\alpha_{2}$ adrenergic receptor agonist in the CeA decreased the sensitizing effect of foot shocks on the amplitude of the acoustic startle response [73]. Furthermore, microinjection of the noradrenergic agonists clonidine in the $\mathrm{CeA}$ increased the tail-flick latency, again supporting a role for noradrenergic receptors in antinociception [74], whereas microinjections of an $\alpha_{2}$ receptor antagonist preceding the induction of stress by restraining, blocked the stress-induced hypoalgesia as measured as the paw- withdrawal latency [14]. Together, these data are consistent with the involvement of the amygdala in stress-induced analgesia and hypoalgesia, triggered by stress-induced release of noradrenaline in this region.

Parabrachial inputs carrying nociceptive information to the $\mathrm{CeA}$ form large glutamatergic synapses on $\mathrm{CeA}$ neurons. As with many other glutamatergic synapses, repetitive stimulation of these inputs results in long-term potentiation (LTP). Synaptic responses are potentiated by an increase in presynaptic transmitter release, which involves the activation of adenylyl cyclase and protein kinase A (PKA) [75]. However, the targets of the signaling pathway are unknown. Interestingly, noradrenergic neuromodulation and the resulting partial block of transmitter release is also mediated presynaptically as a result of the activation of presynaptic $\alpha_{2}$-adrenoceptors activated $\mathrm{G}_{\mathrm{i} / \mathrm{o}}$-G-protein coupled receptors. This in turn, releases $G \beta \gamma$ subunits that act on proteins involved in vesicle fusion with no effect on presynaptic calcium channels [71]. Current insights into transmitter release, such as proteins involved in vesicle release and recycling mainly come from direct presynaptic recordings in the $\mathrm{Ca}-$ lyx of Held [76,77]. In future experiments, the large size of parabrachial terminals may allow for similar recordings to investigate the mechanisms that are engaged during both LTP and noradrenergic modulation of these synapses.

\section{Perspectives}

Studies of the effects of noradrenaline in the amygdala have mainly focused on the modulatory role in emotional memory [78], and evidence for the involvement in pain modulation is relatively sparse. However, over recent years, a role for the amygdala in hypoalgesia and analgesia during emotionally heightened states such as fear has become of more interest. Much evidence has implicated release of noradrenaline, and activation of the $\alpha_{2}$ receptors in the central amygdala in stress-induced analgesia [14]. The parabrachial afferents form large perisomatic excitatory synapses in the central amygdala, and carry nociceptive information into the nociceptive amygdala [43] are key targets for modulation by noradrenaline [71]. Efferent fibers from the CeA project to areas in the brain stem, such as PAG, medulla and pPB, which are involved in descending nociceptive inhibition and are likely to be influenced by amygdala's output. Understanding noradrenalin's hypoalgesic actions at this central relay synapse between pain and heightened emotional states may improve treatment options in nociception.

1 Lang PJ. The emotion probe. Studies of motivation and attention. Am Psychol, 1995, 50: 372-385

2 Wiech K, Tracey I. The influence of negative emotions on pain: behavioral effects and neural mechanisms. Neuroimage, 2009, 47: 987-994

3 Magni G, Moreschi C, Rigatti-Luchini S, Merskey H. Prospective study on the relationship between depressive symptoms and chronic musculoskeletal pain. Pain, 1994, 56: 289-297

4 Carroll LJ, Cassidy JD, Cote P. Depression as a risk factor for onset of an episode of troublesome neck and low back pain. Pain, 2004, 107: $134-139$

5 Kashikar-Zuck S, Goldschneider KR, Powers SW, Vaught MH, Hershey AD. Depression and functional disability in chronic pediatric pain. Clin J Pain, 2001, 17: 341-349

6 Rhudy JL, Meagher MW. Fear and anxiety: divergent effects on human pain thresholds. Pain, 2000, 84: 65-75 
7 Kavaliers M. Brief exposure to a natural predator, the short-tailed weasel, induces benzodiazepine-sensitive analgesia in white-footed mice. Physiol Behav, 1988, 43: 187-193

8 Butler RK, Finn DP. Stress-induced analgesia. Prog Neurobiol, 2009, 88: 184-202

9 van der Kolk BA, Greenberg MS, Orr SP, Pitman RK. Endogenous opioids, stress induced analgesia, and posttraumatic stress disorder. Psychopharmacol Bull, 1989, 25: 417-421

10 McCarty R. Age-related alterations in sympathetic-adrenal medullary responses to stress. Gerontology, 1986, 32: 172-183

11 Morilak DA, Barrera G, Echevarria DJ, Garcia AS, Hernandez A, Ma $\mathrm{S}$, Petre CO. Role of brain norepinephrine in the behavioral response to stress. Prog Neuropsychopharmacol Biol Psychiatry, 2005, 29: 1214-1224

12 Yoshimura M, Furue H. Mechanisms for the anti-nociceptive actions of the descending noradrenergic and serotonergic systems in the spinal cord. J Pharmacol Sci, 2006, 101: 107-117

13 Reddy SV, Yaksh TL. Spinal noradrenergic terminal system mediates antinociception. Brain Res, 1980, 189: 391-401

14 Ortiz JP, Close LN, Heinricher MM, Selden NR. Alpha(2)noradrenergic antagonist administration into the central nucleus of the amygdala blocks stress-induced hypoalgesia in awake behaving rats. Neurosci, 2008, 157: 223-228

15 Pertovaara A. The noradrenergic pain regulation system: a potential target for pain therapy. Eur J Pharmacol, 2013, 716: 2-7

16 Nilsson U. The anxiety- and pain-reducing effects of music interventions: a systematic review. AORN J, 2008, 87: 780-807

17 Morley S. Efficacy and effectiveness of cognitive behaviour therapy for chronic pain: progress and some challenges. Pain, 2011, 152: S99-106

18 Bushnell MC, Ceko M, Low LA. Cognitive and emotional control of pain and its disruption in chronic pain. Nat Rev Neurosci, 2013, 14: 502-511

19 Willis WD, Westlund KN. Neuroanatomy of the pain system and of the pathways that modulate pain. J Clin Neurophysiol, 1997, 14: 2-31

20 Millan MJ. Descending control of pain. Prog Neurobiol, 2002, 66: $355-474$

21 Gauriau C, Bernard JF. Pain pathways and parabrachial circuits in the rat. Exp Physiol, 2002, 87: 251-258

22 Benarroch EE. Pain-autonomic interactions. Neurol Sci, 2006, 27(Suppl 2): S130-133

23 Burstein R, Cliffer KD, Giesler GJ Jr. Cells of origin of the spinohypothalamic tract in the rat. J Comp Neurol, 1990, 291: 329-344

24 Loewy AD, Araujo JC, Kerr FW. Pupillodilator pathways in the brain stem of the cat: anatomical and electrophysiological identification of a central autonomic pathway. Brain Res, 1973, 60: 65-91

25 Purves D, Augustine GJ, Fitzpatrick D. The nociceptive components of the thalamus and cortex. In: Purves D, Augustine G J, Fitzpatrick D, Katz L C, LaMantia AS, McNamara J O, Williams S M, eds. Neuroscience. 2nd ed. Sunderland: Sinauer Associates, 2001

26 Bushnell M C, Duncan G H, Hofbauer R K, Ha B, Chen JI, Carrier B. Pain perception: is there a role for primary somatosensory cortex? Proc Natl Acad Sci USA, 1999, 96: 7705-7709

27 LeDoux J E, Ruggiero D A, Forest R, Stornetta R, Reis DJ. Topographic organization of convergent projections to the thalamus from the inferior colliculus and spinal cord in the rat. J Comp Neurol, 1987, 264: 123-146

28 Turner BH, Herkenham M. Thalamoamygdaloid projections in the rat: a test of the amygdala's role in sensory processing. J Comp Neurol, 1991, 313: 295-325

29 Mayer DJ, Liebeskind JC. Pain reduction by focal electrical stimulation of the brain: an anatomical and behavioral analysis. Brain Res, 1974, 68: 73-93

30 Turner BH, Mishkin M, Knapp M. Organization of the amygdalopetal projections from modality-specific cortical association areas in the monkey. J Comp Neurol, 1980, 191: 515-543

31 McDonald AJ, Mascagni F. Immunohistochemical localization of the beta 2 and beta 3 subunits of the gabaa receptor in the basolateral amygdala of the rat and monkey. Neurosci, 1996, 75: 407-419

32 LeDoux JE, Farb C, Ruggiero DA. Topographic organization of neurons in the acoustic thalamus that project to the amygdala. $\mathrm{J}$ Neurosci, 1990, 10: 1043-1054

33 Pape HC, Pare D. Plastic synaptic networks of the amygdala for the acquisition, expression, and extinction of conditioned fear. Physiol Rev, 2010, 90: 419-463

34 Krettek JE, Price JL. A description of the amygdaloid complex in the rat and cat with observations on intra-amygdaloid axonal connections. J Comp Neurol, 1978, 178: 255-280

35 Sah P, Faber ES, Lopez De Armentia M, Power J. The amygdaloid complex: anatomy and physiology. Physiol Rev, 2003, 83: 803-834

36 Morilak DA, Cecchi M, Khoshbouei H. Interactions of norepinephrine and galanin in the central amygdala and lateral bed nucleus of the stria terminalis modulate the behavioral response to acute stress. Life Sci, 2003, 73: 715-726

37 Shi C, Davis M. Pain pathways involved in fear conditioning measured with fear- potentiated startle: lesion studies. J Neurosci, 1999, 19: 420-430

38 McDonald AJ, Mascagni F, Guo L. Projections of the medial and lateral prefrontal cortices to the amygdala: a phaseolus vulgaris leucoagglutinin study in the rat. Neurosci, 1996, 71: 55-75

39 Bernard JF, Besson JM. The spino(trigemino)pontoamygdaloid pathway: electrophysiological evidence for an involvement in pain processes. J Neurophysiol, 1990, 63: 473-490

40 Saper CB, Loewy AD. Efferent connections of the parabrachial nucleus in the rat. Brain Res, 1980, 197: 291-317

41 Slugg RM, Light AR. Spinal cord and trigeminal projections to the pontine parabrachial region in the rat as demonstrated with phaseolus vulgaris leucoagglutinin. J Comp Neurol, 1994, 339: 49-61

42 Bernard JF, Alden M, Besson JM. The organization of the efferent projections from the pontine parabrachial area to the amygdaloid complex: a phaseolus vulgaris leucoagglutinin (pha-1) study in the rat. J Comp Neurol, 1993, 329: 201-229

43 Sarhan M, Freund-Mercier MJ, Veinante P. Branching patterns of parabrachial neurons projecting to the central extended amgydala: single axonal reconstructions. J Comp Neurol, 2005, 491: 418-442

44 Jhamandas JH, Petrov T, Harris KH, Vu T, Krukoff TL. Parabrachial nucleus projection to the amygdala in the rat: electrophysiological and anatomical observations. Brain Res Bull, 1996, 39: 115-126

45 Bernard JF, Huang GF, Besson JM. The parabrachial area: electrophysiological evidence for an involvement in visceral nociceptive processes. J Neurophysiol, 1994, 71: 1646-1660

46 Bernard JF, Huang GF, Besson JM. Nucleus centralis of the amygdala and the globus pallidus ventralis: electrophysiological evidence for an involvement in pain processes. J Neurophysiol, 1992, 68: 551-569

47 Neugebauer V, Li W. Processing of nociceptive mechanical and thermal information in central amygdala neurons with knee-joint input. J Neurophysiol, 2002, 87: 103-112

48 Bingel U, Quante M, Knab R, Bromm B, Weiller C, Büchel C. Subcortical structures involved in pain processing: evidence from single-trial fMRI. Pain, 2002, 99: 313-321

49 LeDoux J E, Iwata J, Cicchetti P, Reis DJ. Different projections of the central amygdaloid nucleus mediate autonomic and behavioural correlates of conditioned fear. J Neurosci, 1988, 8: 2517-2529

50 Bourgeais L, Gauriau C, Bernard JF. Projections from the nociceptive area of the central nucleus of the amygdala to the forebrain: a pha-1 study in the rat. Eur J Neurosci, 2001, 14: 229-255

51 Veening JG, Swanson LW, Sawchenko PE. The organization of projections from the central nucleus of the amygdala to brainstem sites involved in central autonomic regulation: a combined retrograde transport-immunohistochemical study. Brain Res, 1984, 303: 337357

52 Rizvi TA, Ennis M, Behbehani MM, Shipley MT. Connections between the central nucleus of the amygdala and the midbrain periaqueductal gray: topography and reciprocity. J Comp Neurol, 1991, 303: 121-131 
53 Helmstetter FJ, Tershner SA, Poore LH, Bellgowan PS. Antinociception following opioid stimulation of the basolateral amygdala is expressed through the periaqueductal gray and rostral ventromedial medulla. Brain Res, 1998, 779: 104-118

54 Behbehani MM. Functional characteristics of the midbrain periaqueductal gray. Prog Neurobiol, 1995, 46: 575-605

55 Neugebauer V, Li W, Bird G C, Han JS. The amygdala and persistent pain. Neuroscientist, 2004, 10: 221-234

56 Crown E D, King T E, Meagher M W, Grau JW. Shock-induced hyperalgesia: III. Role of the bed nucleus of the stria terminalis and amygdaloid nuclei. Behav Neurosci, 2000, 114: 561-573

57 Calvino B, Levesque G, Besson JM. Possible involvement of the amygdaloid complex in morphine analgesia as studied by electrolytic lesions in rats. Brain Res, 1982, 233: 221-226

58 Mena NB, Mathur R, Nayar U. Amygdalar involvement in pain. Indian J Physiol Pharmacol, 1995, 39: 339-346

59 Fox RJ, Sorenson CA. Bilateral lesions of the amygdala attenuate analgesia induced by diverse environmental challenges. Brain Res, 1994, 648: 215-221

60 Fallon JH, Koziell DA, Moore RY. Catecholamine innervation of the basal forebrain. II. Amygdala, suprarhinal cortex and entorhinal cortex. J Comp Neurol, 1978, 180: 509-532

61 Zardetto-Smith AM, Gray TS. Catecholamine and npy efferents from the ventrolateral medulla to the amygdala in the rat. Brain Res Bull, 1995, 38: 253-260

62 Tanaka T, Yokoo H, Mizoguchi K, Yoshida M, Tsuda A, Tanaka M. Noradrenaline release in the rat amygdala is increased by stress: studies with intracerebral microdialysis. Brain Res, 1991, 544: 174-176

63 Khoshbouei H, Cecchi M, Dove S, Javors M, Morilak DA. Behavioral reactivity to stress: amplification of stress-induced noradrenergic activation elicits a galanin-mediated anxiolytic effect in central amygdala. Pharmacol Biochem Behav, 2002, 71: 407-417

64 Nalepa I, Vetulani J, Borghi V, Kowalska M, Przewłocka B, Pavone F. Formalin hindpaw injection induces changes in the $[3 \mathrm{H}]$ prazosin binding to alpha1-adrenoceptors in specific regions of the mouse brain and spinal cord. J Neural Transm, 2005, 112: 1309-1319

65 Acosta-Martinez M, Fiber JM, Brown RD, Etgen AM. Localization of alphalb-adrenergic receptor in female rat brain regions involved in stress and neuroendocrine function. Neurochem Int, 1999, 35:
383-391

66 Talley E M, Rosin D L, Lee A, Guyenet PG, Lynch KR. Distribution of alpha 2a-adrenergic receptor-like immunoreactivity in the rat central nervous system. J Comp Neurol, 1996, 372: 111-134

67 Rosin D L, Talley E M, Lee A, Stornetta RL, Gaylinn BD, Guyenet PG, Lynch KR. Distribution of alpha 2c-adrenergic receptor-like immunoreactivity in the rat central nervous system. J Comp Neurol, 1996, 372: 135-165

68 Scheinin M, Lomasney JW, Hayden-Hixson DM, Schambra UB, Caron MG, Lefkowitz RJ, Fremeau RT Jr. Distribution of alpha 2 -adrenergic receptor subtype gene expression in rat brain. Brain Res Mol Brain Res, 1994, 21: 133-149

69 Wanaka A, Kiyama H, Murakami T, Matsumoto M, Kamada T, Malbon CC, Tohyama M. Immunocytochemical localization of beta-adrenergic receptors in the rat brain. Brain Res, 1989, 485: $125-140$

70 Zaldivar A, Krichmar JL. Interactions between the neuromodulatory systems and the amygdala: exploratory survey using the allen mouse brain atlas. Brain Struct Funct, 2013, 218: 1513-1530

71 Delaney AJ, Crane JW, Sah P. Noradrenaline modulates transmission at a central synapse by a presynaptic mechanism. Neuron, 2007, 56: 880-892

72 Boyd RE. Alpha2-adrenergic receptor agonists as analgesics. Curr Top Med Chem, 2001, 1: 193-197

73 Fendt M, Koch M, Schnitzler HU. Amygdaloid noradrenaline is involved in the sensitization of the acoustic startle response in rats. Pharmacol Biochem Behav, 1994, 48: 307-314

74 Ortiz JP, Heinricher MM, Selden NR. Noradrenergic agonist administration into the central nucleus of the amygdala increases the tail-flick latency in lightly anesthetized rats. Neurosci, 2007, 148: 737-743

75 Lopez de Armentia M, Sah P. Bidirectional synaptic plasticity at nociceptive afferents in the rat central amygdala. J Physiol, 2007, 581: 961-970

76 Sun JY, Wu LG. Fast kinetics of exocytosis revealed by simultaneous measurements of presynaptic capacitance and postsynaptic currents at a central synapse. Neuron, 2001, 30: 171-182

77 Schneggenburger R, Forsythe ID. The calyx of held. Cell Tissue Res, 2006, 326: 311-337

78 van Stegeren $\mathrm{AH}$. The role of the noradrenergic system in emotional memory. Acta Psychol, 2008, 127: 532-541

Open Access This article is distributed under the terms of the Creative Commons Attribution License which permits any use, distribution, and reproduction in any medium, provided the original author(s) and source are credited. 